\title{
Effect of ocrelizumab on vaccine responses in patients with multiple sclerosis
}

\section{The VELOCE study}

Amit Bar-Or, MD, FRCPC, Jonathan C. Calkwood, MD, Cathy Chognot, PhD, Joanna Evershed, BSc, Edward J. Fox, MD, PhD, Ann Herman, PhD, Marianna Manfrini, MD, PhD, John McNamara, MSc, Derrick S. Robertson, MD, Daniela Stokmaier, PhD, Jeanette K. Wendt, MD, Kevin L. Winthrop, MD, MPH, and Anthony Traboulsee, MD, FRCPC

Neurology ${ }^{\circledR}$ 2020;95:e1999-e2008. doi:10.1212/WNL.0000000000010380

\section{Abstract}

\section{Objective}

The phase IIIb A Study to Evaluate the Effects of Ocrelizumab on Immune Responses in Participants With Relapsing Forms of Multiple Sclerosis (VELOCE) study (NCT02545868) assessed responses to selected vaccines in ocrelizumab (OCR)-treated patients with relapsing multiple sclerosis.

\section{Methods}

Patients were randomized 2:1 into the OCR group $(\mathrm{n}=68$; OCR $600 \mathrm{mg})$ or control group $(\mathrm{n}=34$; interferon beta or no disease-modifying therapy). All received tetanus toxoid (TT)-containing vaccine, Pneumovax (23-valent pneumococcal polysaccharide vaccine [23-PPV]), and keyhole limpet hemocyanin $(\mathrm{KLH})$. The OCR group was subdivided into OCR1 $(\mathrm{n}=33)$ and OCR2 $(\mathrm{n}=$ 35) at randomization. The OCR1 group received Prevnar (13-valent conjugate pneumococcal vaccine) 4 weeks after 23-PPV; the OCR2 and control groups received influenza vaccine. Vaccinations started 12 weeks after OCR initiation (OCR group) or on day 1 (control group).

\section{Results}

Positive response rate to TT vaccine at 8 weeks was $23.9 \%$ in the OCR vs $54.5 \%$ in the control group. Positive response rate to $\geq 5$ serotypes in 23 -PPV at 4 weeks was $71.6 \%$ in the OCR and $100 \%$ in the control group. Prevnar did not enhance response to pneumococcal serotypes in common with Pneumovax. Humoral response to KLH was decreased in the OCR vs control group. Seroprotection rates at 4 weeks against 5 influenza strains ranged from $55.6 \%$ to $80.0 \%$ in the OCR2 group and $75.0 \%$ to $97.0 \%$ in the control group.

\section{Conclusion}

Peripherally B-cell-depleted OCR recipients mounted attenuated humoral responses to clinically relevant vaccines and the neoantigen $\mathrm{KLH}$, suggesting that use of standard nonlive vaccines while on OCR treatment remains a consideration. For seasonal influenza vaccines, it is recommended to vaccinate patients on OCR because a potentially protective humoral response, even if attenuated, can be expected.

\section{Classification of evidence}

This study provides Class II evidence confirming that the humoral response to nonlive vaccines in patients with relapsing multiple sclerosis after OCR treatment is attenuated compared with untreated or interferon beta-treated patients, but they can still be expected to be protective.

\author{
Correspondence \\ Dr. Bar-Or \\ amitbar@ \\ pennmedicine.upenn.edu
}

\section{RELATED ARTICLE}

\section{Editorial}

Vaccination in B-cell-depleted patients with multiple sclerosis

Page 613

\section{MORE ONLINE}

\section{$\rightarrow$ Class of Evidence}

Criteria for rating

therapeutic and diagnostic studies

NPub.org/coe

\section{ค Podcast}

Dr. David Lapides talks with Dr. Amit Bar-Or about his paper discussing vaccine response in patients with MS.

NPub.org/ah4etj

\section{Clinicaltrials.gov identifier NCT02545868.}

\footnotetext{
From the Department of Neurology and Center for Neuroinflammation and Experimental Therapeutics (A.B.-O.), Perelman School of Medicine, University of Pennsylvania, Philadelphia; The Minneapolis Clinic of Neurology (J.C.C.), MN; F. Hoffmann-La Roche Ltd (C.C., J.E., M.M., D.S.), Basel, Switzerland; Central Texas Neurology Consultants (E.J.F.), Round Rock; Genentech, Inc (A.H.), South San Francisco, CA; John McNamara Consulting Ltd (J.M.), Cambridge, UK; Department of Neurology (D.S.R.), Multiple Sclerosis Division, University of South Florida College of Medicine, Tampa; Territory Neurology and Research Institution (J.K.W.), Tucson, AZ; Division of Infectious Diseases (K.L.W.), Oregon Health \& Science University, Portland; and University of British Columbia (A.T.), Vancouver, Canada.

Go to Neurology.org/N for full disclosures. Funding information and disclosures deemed relevant by the authors, if any, are provided at the end of the article.
} 


\section{Glossary}

$\mathbf{C I}=$ confidence interval; CTCAE $=$ Common Terminology Criteria for Adverse Events; DMT = disease-modifying treatment; HI = hemagglutination inhibition; IFN = interferon; Ig = immunoglobulin; KLH = keyhole limpet hemocyanin; MS = multiple sclerosis; OCR = ocrelizumab; PPMS = primary progressive MS; RMS = relapsing MS; 13-PCV = 13-valent conjugate pneumococcal vaccine; $\mathbf{T T}=$ tetanus toxoid; $23-\mathrm{PPV}=23$-valent pneumococcal polysaccharide vaccine; VELOCE $=$ A Study to Evaluate the Effects of Ocrelizumab on Immune Responses in Participants With Relapsing Forms of Multiple Sclerosis.

Vaccination against communicable diseases is part of general health maintenance and an important aspect of multiple sclerosis (MS) disease management because infections can exacerbate MS symptoms and are a recognized complication of some MS therapies. Ocrelizumab (OCR), a CD20-selective humanized monoclonal antibody approved for the treatment of relapsing MS (RMS) and primary progressive MS (PPMS), depletes $\mathrm{CD}_{20} \mathrm{~B}^{\mathrm{B}}$ cells $^{1,2}$ while preserving the capacity for B-cell reconstitution and preexisting humoral immunity. ${ }^{3,4}$ As of August $2019,>120,000$ patients with MS have initiated OCR therapy globally as part of clinical trials and postmarketing experience, amounting to a total of $>120,000$ patient-years.

Heretofore, no formal assessments of the impact of OCR on vaccine response have been conducted. This report details the findings of A Study to Evaluate the Effects of Ocrelizumab on Immune Responses in Participants With Relapsing Forms of Multiple Sclerosis (VELOCE; NCT02545868), a phase IIIb, multicenter, open-label study evaluating the effectiveness of vaccinations in OCR-treated patients with RMS.

\section{Methods}

\section{Standard protocol approvals, registrations, and patient consents}

This study (ClinicalTrials.gov identifier NCT02545868) was performed in accordance with the Declaration of Helsinki and the principles of Good Clinical Practice. The protocol was approved by an Institutional Review Board at each investigative site. All patients provided written informed consent.

\section{Patients}

Adult patients (18-55 years old) with $\mathrm{RMS}^{5}$ (baseline Expanded Disability Status Scale score $0-5.5$ ) who received $\geq 1$ tetanus toxoid (TT)-containing vaccination (tetanus and diphtheria or tetanus, diphtheria, and acellular pertussis) $>2$ years before screening were enrolled across 19 centers in the United States and 2 centers in Canada between October 2015 and August 2016.

Patients were excluded if they had positive serum $\beta$-human chorionic gonadotropin tests at screening; prior immunization with TT-containing vaccine within 2 years of screening, 23-valent pneumococcal polysaccharide vaccine (23-PPV) within 5 years of screening, World Health Organizationrecommended 2015/2016 or 2016/2017 seasonal influenza vaccine for the Northern Hemisphere (if scheduled per protocol to receive these vaccines), or keyhole limpet hemocyanin $(\mathrm{KLH})$; prior treatment with B-cell-targeted therapies (e.g., rituximab or OCR), lymphocyte-trafficking blockers, alemtuzumab, anti-CD4, cladribine, cyclophosphamide, mitoxantrone, azathioprine, mycophenolate mofetil, cyclosporine, methotrexate, total body irradiation, or bone marrow transplantation; or levels of serum immunoglobulin ( $\mathrm{Ig}$ ) $\mathrm{G} \geq 18 \%$ below the lower limit of normal $(<4.6 \mathrm{~g} / \mathrm{L})$ or levels of serum $\operatorname{IgM} \geq 8 \%$ below the lower limit of normal $(<0.37 \mathrm{~g} / \mathrm{L})$.

\section{Study design}

The VELOCE study included phases for screening, immunization, safety follow-up, and continued B-cell monitoring; an optional OCR extension was also available for qualifying patients (figure 1). Eligible patients were randomized $(2: 1)$ via an interactive response system (Almac Clinical Technologies, San Francisco, CA) either to OCR (administered as two 300-mg IV infusions separated by 14 days) or to a control group in which patients either continued their current interferon (IFN) beta therapy (allowed owing to the reported absence of effects on vaccine responses ${ }^{6-9}$ ) or received no disease-modifying treatment (DMT). Patients randomized to OCR were further divided into 2 groups: OCR1 (patients received additional 13-valent conjugate pneumococcal vaccine $[13-\mathrm{PCV}]$ booster for 23-PPV) and OCR2 (patients received World Health Organization-recommended 2015/ 2016 or 2016/2017 seasonal influenza vaccine for the Northern Hemisphere containing 3 or 4 of the 5 strains studied [influenza A/California/7/2009 (H1N1CA09), influenza B/Phuket/3073/2013 (BPHU13), influenza A/ Switzerland/97 15293/2013 (H3N2SW13), influenza B/ Brisbane/60/2008 (BBRIS08), influenza A/Hong Kong/ 4801/2014 (AHK4801)]). Assignment of patients receiving OCR to OCR1 or OCR2 was not randomized but based on a recruitment schedule that maximized the probability of patients in the OCR2 and control groups receiving the same influenza vaccine. Premedication per prescribing information was mandatory before OCR administration.

Several antigens were studied to evaluate different immune response pathways after OCR administration. Commercially available vaccines (TT containing; 23-PPV [Pneumovax, Merck and Co, Kenilworth, NJ]; 13-PCV [Prevnar, Wyeth Pharmaceuticals, Philadelphia, PA]; seasonal influenza) were supplied locally by the trial sites and were administered as single deltoid intramuscular injections according to local label. 


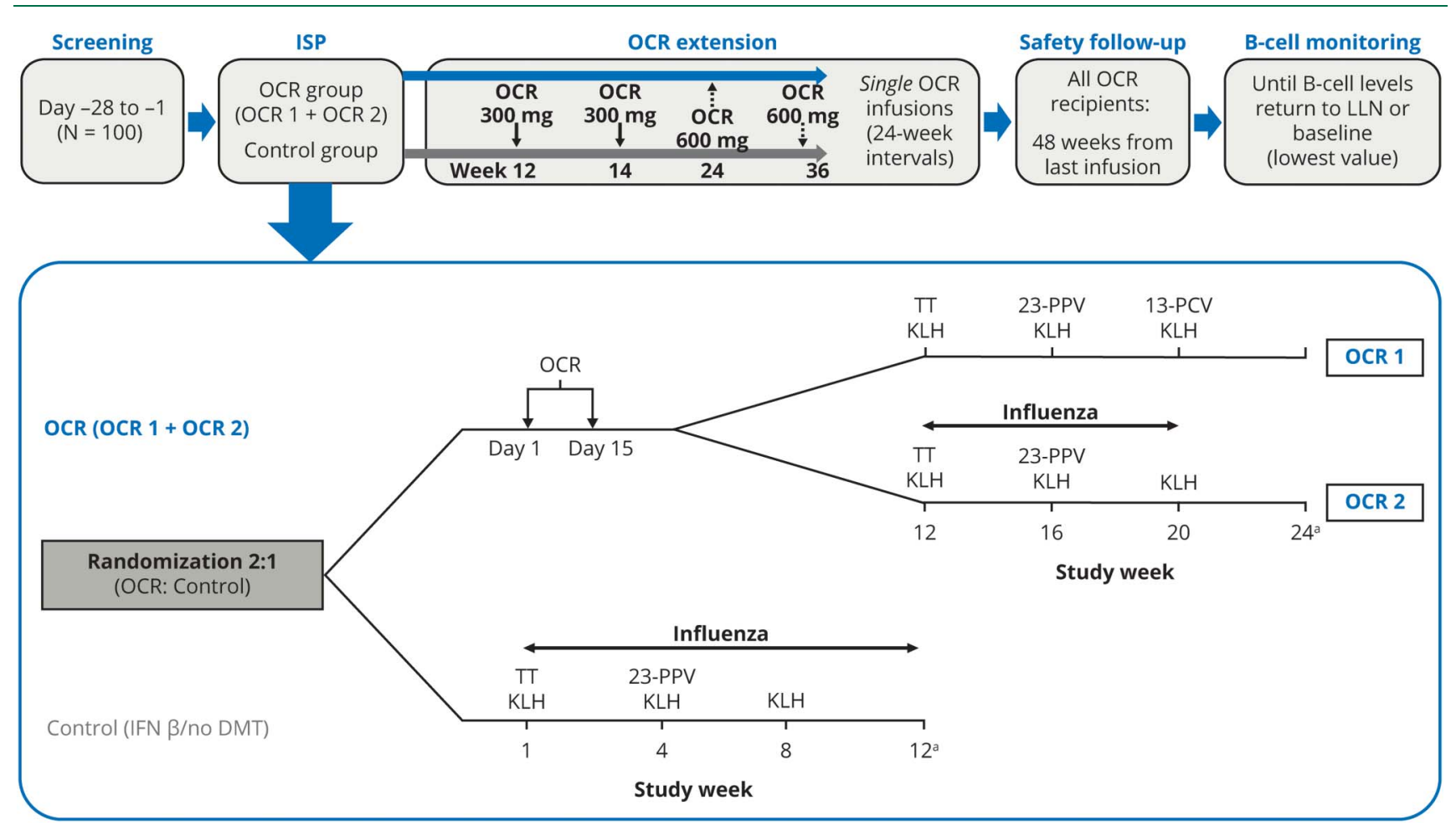

ammunization study period (ISP) duration: ocrelizumab (OCR) group (OCR1 + OCR2) 24 weeks, control group 12 weeks. DMT = disease-modifying therapy; IFN = interferon; $\mathrm{KLH}=$ keyhole limpet hemocyanin; $\mathrm{LLN}=$ lower limit of normal; 13-PCV = 13-valent pneumococcal conjugate vaccine; TT = tetanus toxoidcontaining vaccine; 23-PPV = 23-valent pneumococcal polysaccharide vaccine; VELOCE = A Study to Evaluate the Effects of Ocrelizumab on Immune Responses in Participants With Relapsing Forms of Multiple Sclerosis.

In addition, the neoantigen $\mathrm{KLH}(1 \mathrm{mg})$, which was provided by the sponsor, was administered subcutaneously at 3 time points during the study (figure 1).

While the majority of B-cell depletion occurs soon after the initiation of anti-CD20 treatment, it is thought that some additional B-cell depletion occurs in the subsequent weeks, given the relatively long half-life of the antibody and the fact that other B cells move to areas that would be accessible for depletion. To properly evaluate the effects of more complete peripheral B-cell depletion on the immune response to vaccinations, patients in the OCR group did not receive vaccinations until 12 weeks after treatment. In the control group, vaccinations were administered starting immediately after randomization to facilitate the shortest immunization study period possible, enabling these patients either to progress to the open-label extension or to start another DMT after primary study completion. Patients who withdrew after randomization were not replaced.

\section{Study endpoints}

The primary endpoint was the proportion of patients with a positive response to TT-containing booster vaccine measured 8 weeks after vaccination. A positive response to the vaccine was defined as an anti-TT IgG antibody titer $\geq 0.2$ $\mathrm{IU} / \mathrm{mL}$ in patients with prevaccination titers $<0.1 \mathrm{IU} / \mathrm{mL}$ or $\geq 4$-fold increase in antibody titer in patients with prevaccination antibody titers $\geq 0.1 \mathrm{IU} / \mathrm{mL}$. Response to TT-containing vaccine 4 weeks after vaccination was also assessed as a secondary endpoint, using both the same definition of positive response as the primary endpoint and a modified definition of positive response in patients with a prevaccination titer $\geq 0.1 \mathrm{IU} / \mathrm{mL}$ ( $\geq 2$-fold increase vs prevaccination titer). Additional secondary endpoints were (1) response to 23-PPV vaccine 4 weeks after vaccination and 23-PPV vaccine boosted by 13-PCV 4 weeks after 13-PCV vaccination, with a positive response defined as 2 -fold or $>1 \mu \mathrm{g} / \mathrm{mL}$ increase in serotype-specific antibody titers (IgG) vs prevaccination titers; (2) mean titers of anti-KLH antibodies (IgG and IgM) measured 4, 8, and 12 weeks after the first KLH administration; and (3) seroprotection and seroconversion to seasonal (2015/2016 or 2016/2017) influenza vaccine 4 weeks after vaccination (influenza strain-specific hemagglutination inhibition [HI] titers measured 4 weeks after vaccination compared to prevaccination titers). Strainspecific seroprotection was defined as HI titers $>40$, and seroconversion was either defined as $\geq 4$-fold increase in $\mathrm{HI}$ titers after vaccination (in patients with prevaccination $\mathrm{HI}$ titers $\geq 10$ ) or postvaccination HI titers $\geq 40$ (in patients with prevaccination HI titers <10; US Food and Drug Administration guidance for industry ${ }^{10}$ ) or defined as postvaccination $\mathrm{HI}$ titers $>40$ in patients with prevaccination titers $<10$ (per study protocol). 
Assessments of responses to TT-containing vaccine, 23-PPV, and $\mathrm{KLH}$ compared all OCR recipients to patients in the control group; responses to influenza vaccine (OCR2) and the boosting effect of 13-PCV on shared serotypes with 23PPV (OCR1) were compared to the control group.

\section{Analytical assays}

Commercially available ELISAs (VaccZyme Anti-Tetanus Toxoid IgG Enzyme Immunoassay Kit [The Binding Site Group Ltd, Birmingham, UK]; KLH IgG and IgM assay [Alpha Diagnostic Intl Inc., San Antonio, TX]) were used to determine responses to TT-containing vaccine ( $\operatorname{IgG}$ ) and $\mathrm{KLH}$ (IgG and IgM) with TT and KLH used as capturing agents in the respective assays. Serotype-specific vaccineinduced IgG to pneumococcal polysaccharide antigens was determined by bead-based multianalyte immunodetection using Luminex MagPlex Microspheres (Luminex Corp, Austin, TX). The HI assay was used to measure strain-specific anti-influenza titers. The reported HI titer is the highest serum dilution-blocking hemagglutination.

\section{Statistical analyses}

\section{Study size}

The enrollment of $\approx 100$ patients was based on an expected $70 \%$ response rate to the primary endpoint in the OCR (all) and control groups with an expected half-width of the $95 \%$ confidence interval (CI) of the difference between the 2 response rates being 0.201 .

\section{Analysis populations}

Immunologic results from the observed population (immunization period completers summarized according to randomized treatment) and safety measures from the safety population (all patients who received treatment or vaccination, summarized by treatment received) are presented.

\section{Endpoint analyses}

Immunology endpoint data were masked during analysis to prevent introduction of bias. Descriptive statistics were used to describe response rates to endpoints; $95 \%$ CIs of betweengroup differences were obtained by the normal approximation method. Response rates to the 23 individual serotypes within 23-PPV and grouped responses to $\geq 2,3,4,5$, and 12 serotypes were calculated. In addition, 13-PCV-boosted responses to the serotypes in common with 23-PPV $(1,3,4,5,6 \mathrm{~B}, 7 \mathrm{~F}, 9 \mathrm{~V}$, $14,18 \mathrm{C}, 19 \mathrm{~A}, 19 \mathrm{~F}$, and $23 \mathrm{~F}$ ) in patients in the OCR1 group were compared with responses in patients in the OCR2 and control groups.

\section{Data availability}

Qualified researchers may request access to individual patient-level data through the clinical study data request platform (clinicalstudydatarequest.com). Further details on Roche's criteria for eligible studies are available here: clinicalstudydatarequest.com/Study-Sponsors/Study-

Sponsors-Roche.aspx. For further details on Roche's Global Policy on the Sharing of Clinical Information and how to request access to related clinical study documents, see here: roche.com/research_and_development/who_ we_are_how_we_work/clinical_trials/our_commitment_to_data_sharing.htm.

\section{Results}

\section{Classification of evidence}

The primary research question of this interventional study was to determine whether responses were mounted to selected vaccines in OCR-treated patients with RMS. The VELOCE study provided Class II evidence that peripherally Bcell-depleted OCR recipients mounted attenuated humoral responses to clinically relevant vaccines and the neoantigen, $\mathrm{KLH}$, suggesting that use of standard nonlive vaccines while on OCR treatment remains a consideration. For seasonal influenza vaccines, it is recommended to vaccinate patients on OCR because a potentially protective humoral response, even if attenuated, can be expected.

\section{Patient disposition}

A total of 102 patients were randomized (OCR [all] $\mathrm{n}=68$, control $n=34)$. All patients completed the immunization period and entered the optional OCR extension period. Patient disposition is presented in figure e-1 (available from Dryad, doi.org/10.5061/dryad.crjdfn31d). All patients randomized to OCR treatment received their single dose of OCR.

\section{Baseline demographic and disease characteristics}

Demographic characteristics and vaccination/passive immunization histories between the OCR (all) and control groups were generally well balanced; however, in the OCR (all) group compared to the control group, there was a lower proportion of female patients (66.2\% vs $79.4 \%)$, a higher mean [SD] body mass index (28.9 [6.7] vs $\left.26.6[5.7] \mathrm{kg} / \mathrm{m}^{2}\right)$, and a higher mean [SD] T1 gadolinium-enhancing lesion load (2.9 [10.9] vs 0.6 [2.7]) (table 1 ). The majority of patients had not received prior DMT (OCR 54\%, control 68\%); IFN$\beta-1$ and glatiramer acetate were the most commonly used prior DMTs. Twelve patients (35\%) randomized to the control group continued with IFN- $\beta$ during the immunization period.

\section{Response to TT-containing vaccine}

Prevaccination anti-tetanus antibody ( $\mathrm{IgG}$ ) geometric mean titers in the OCR (all) group patients $(1.68 \mathrm{IU} / \mathrm{mL}$ ) and control group patients $(2.15 \mathrm{IU} / \mathrm{mL})$ were comparable (figure 2A) and markedly higher than the seroprotective titer level $(0.1 \mathrm{IU} / \mathrm{mL})$. Anti-TT antibody levels increased in both groups by postvaccination weeks 4 and 8 ; however, levels were higher in control group patients vs those in the OCR (all) group. Three patients in the OCR group had prevaccination titers $(0.05-0.08 \mathrm{IU} / \mathrm{mL})$ that were not seroprotective; all 3 patients achieved seroprotection and a positive response 
Table 1 Baseline demographic and disease characteristics

\begin{tabular}{|c|c|c|}
\hline Parameter & OCR $600 \mathrm{mg}$ (all) $(n=68)$ & Control (IFN- $\left.\beta^{\mathrm{a}} / \mathrm{no} \mathrm{DMT}\right)(\mathrm{n}=34)$ \\
\hline Age, mean (SD), y & $39.7(8.9)$ & $41.4(7.9)$ \\
\hline Female, $\mathbf{n}(\%)$ & $45(66.2)$ & $27(79.4)$ \\
\hline White, n (\%) & $64(94.1)$ & $30(88.2)$ \\
\hline BMI, mean (SD), kg/m² & $28.9(6.7)^{\mathrm{b}}$ & $26.6(5.7)^{c}$ \\
\hline Duration since MS symptom onset, mean (SD), y & $8.9(7.1)$ & $9.5(5.9)$ \\
\hline Duration since RMS diagnosis, mean (SD), y & $6.6(6.6)$ & $7.1(5.2)$ \\
\hline Baseline EDSS score, mean (SD) & $2.7(1.3)$ & $2.3(1.4)$ \\
\hline Patients with T1 gadolinium-enhancing lesions, $n$ (\%) & $21(32.3)^{d}$ & $3(8.8)$ \\
\hline >1 T1 gadolinium-enhancing lesions, $n(\%)$ & $13(20.0)^{d}$ & $3(8.8)$ \\
\hline T1 gadolinium-enhancing lesions, mean (SD), n & $2.9(10.9)^{d}$ & $0.6(2.7)$ \\
\hline T2 lesions, mean (SD), $n$ & $57.9(45.4)^{\mathrm{e}}$ & $45.5(28.6)$ \\
\hline T2 lesion volume, mean (SD), $\mathrm{cm}^{3}$ & $10.8(13.3)^{\mathrm{e}}$ & $7.5(8.2)$ \\
\hline
\end{tabular}

Abbreviations: $\mathrm{BMI}=$ body mass index; DMT = disease-modifying therapy; EDSS = Expanded Disability Status Scale; IFN- $\beta=$ interferon beta; MS = multiple sclerosis; OCR = ocrelizumab; RMS = relapsing MS

a Twelve patients (35\%) randomized to the control group continued with IFN- $\beta$ during the immunization period.

${ }^{\mathrm{b}} \mathrm{n}=64$.

${ }^{\mathrm{c}} \mathrm{n}=33$.

${ }^{d} \mathrm{n}=65$.

${ }^{e} n=66$.

4 weeks $(0.63-3.50 \mathrm{IU} / \mathrm{mL})$ and 8 weeks after vaccination $(0.47-1.72 \mathrm{IU} / \mathrm{mL})$.

Similarly, postvaccination positive response rates (using the criterion of $\geq 4$-fold increase from prevaccination antibody level) were lower in the OCR (all) group (figure 2B). Thus, for the primary endpoint, the proportion of patients with a positive response at 8 weeks after vaccination was $23.9 \%(\mathrm{n}=$ 16 of 67$)$ in the OCR (all) group vs $54.5 \%(\mathrm{n}=18$ of 33$)$ in the control group, with a treatment difference of $-30.7 \%$ (95\% CI $-10.8 \%$ to $-50.5 \%$ ).

\section{Response to pneumococcal vaccines}

Prevaccination pneumococcal serotype-specific geometric mean titers (IgG) for all 23 serotypes within 23-PPV in the OCR (all) and control groups were comparable; serotypespecific geometric mean titers before vaccination and 4 and 8 weeks after vaccination are presented in table e-2 (available from Dryad, doi.org/10.5061/dryad.crjdfn31d). The proportion of patients in the OCR (all) group who had positive responses (using protocol-defined criteria of $\geq 2$-fold or $>1-\mu \mathrm{g} / \mathrm{mL}$ increase in serotype-specific antibody titers $[\mathrm{IgG}]$ vs prevaccination titers) to individual pneumococcal serotypes at 4 weeks after vaccination (figure $3 \mathrm{~A}$ ) ranged from $20.9 \%$ for serotypes $12 \mathrm{~F}$ and 20 (n $=14$ of 68$)$ to $64.2 \%$ for serotype $8(n=43$ of 68$)$. Patterns of response were similar at 8 weeks after administration; between-group differences (OCR [all] minus control group) in the proportion of patients with a positive response for all 23 serotypes ranged from $-62.8 \%$ to $-25.0 \%$ after 4 weeks and $-65.3 \%$ to $-19.1 \%$ after 8 weeks after vaccination. The proportion of patients with a positive response to $\geq 2,3,4,5$, or 12 of the 23 serotypes within 23 $\mathrm{PPV}$ is presented in figure $3 \mathrm{~B}$; positive response rate to $\geq 5$ serotypes at 4 weeks was $71.6 \%$ in the OCR group and $100 \%$ in the control group with a trend for a roughly linear decrease in response rate with increasing numbers of serotypes observed in the OCR (all) group. Comparison of responses in the OCR1 (who received a 13-PCV booster) and OCR2 groups demonstrated that the positive response rates to 12 common serotypes present in the 13-PCV booster were not markedly increased when assessed 4 weeks after 13-PCV administration (figure e-2, available from Dryad, doi.org/10.5061/dryad.crjdfn31d). Of note, protective antibody levels for pneumococcal vaccines have not been established.

\section{Response to influenza vaccine}

Prevaccination titers (HI units) were higher in the OCR2 vs control group for influenza strains H1N1CA09 (66.3 vs 39.6), BPHU13 (49.3 vs 27.1), H3N2SW13 (65.7 vs 26.1), and AHK4801 (52.8 vs 24.4), whereas titers for BBRIS08 were comparable (33.7 vs 36.7 ). Increases in the HI titer were lower in the OCR2 group vs the control group; however, titers increased in both groups for all strains 4 weeks after vaccination (table 2). Seroprotection rates in OCR recipients to all strains were higher after vaccination $(55.6 \%-80.0 \%)$ than before vaccination $(20.0 \%-60.0 \%)$; however, postvaccination seroprotection rates were lower than in the control group (75.0\%-97.0\%; figure 4). In OCR recipients, seroconversion 
Figure 2 Response (IgG) to tetanus toxoid-containing vaccine

A

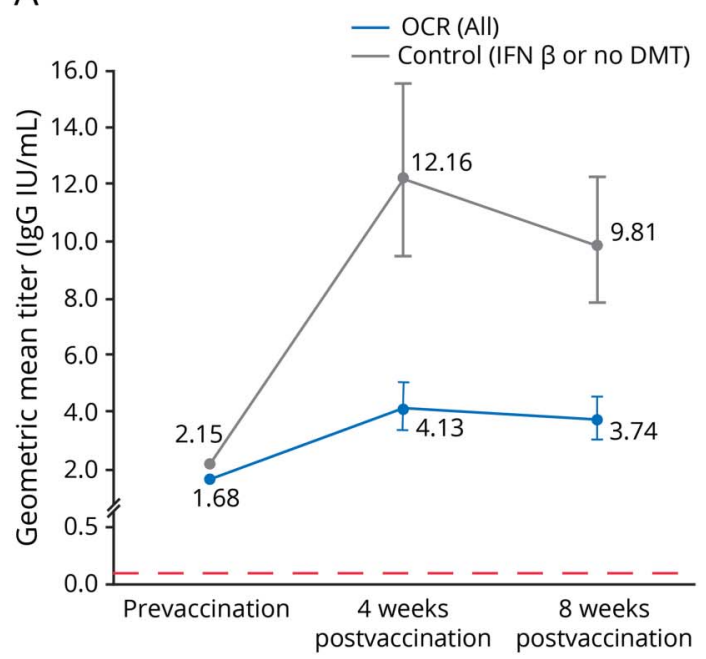

B

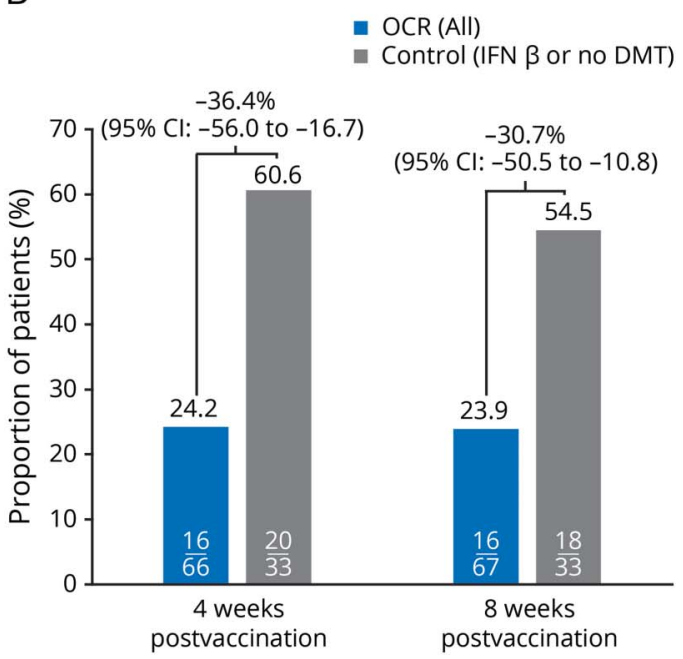

(A) Anti-tetanus titers and (B) proportion of patients with $\geq 4$-fold increase in tetanus antibody titer. Positive response defined as $\geq 4$-fold increase in antibody titer measured 8 weeks after vaccination compared with prevaccination titer (if prevaccination titer was $\geq 0.1 \mathrm{IU} / \mathrm{mL}$ ) or an antibody titer $\geq 0.2 \mathrm{IU} / \mathrm{mL}$ if prevaccination titer was $<0.1 \mathrm{IU} / \mathrm{mL}$. Dotted red line represents protective titer level. $\mathrm{Cl}=$ confidence interval; $\mathrm{DMT}=$ disease-modifying therapy; IFN = interferon; IgG = immunoglobulin G; OCR = ocrelizumab.

rates were lower per US Food and Drug Administration guidance for industry $(10.0 \%-60.0 \%)$ and per protocol $(0 \%-42.9 \%)$ than in the control group $(53.3 \%-88.5 \%$ and $25.0 \%-100 \%$, respectively). However, the interpretability of seroconversion per protocol was limited by the small number of patients with seronegative prevaccination titers $(\mathrm{HI}<10)$ in both groups (table e-1, available from Dryad, doi.org/10. 5061/dryad.crjdfn31d). An exploratory analysis showed no relationship between the timing of influenza vaccination in relation to OCR administration and the degree of response (data not shown).

\section{Response to KLH neoantigen}

Preadministration geometric mean anti-KLH antibody titers (IgM and IgG) in the OCR (all) group (IgM 100 units, IgG 274 units) and control group (IgM 130 units, IgG 235 units) were comparable. Postadministration IgM and IgG titers were higher in the control group vs OCR (all) group at 4 weeks

Figure 3 Response (IgG) to pneumococcal vaccine

A

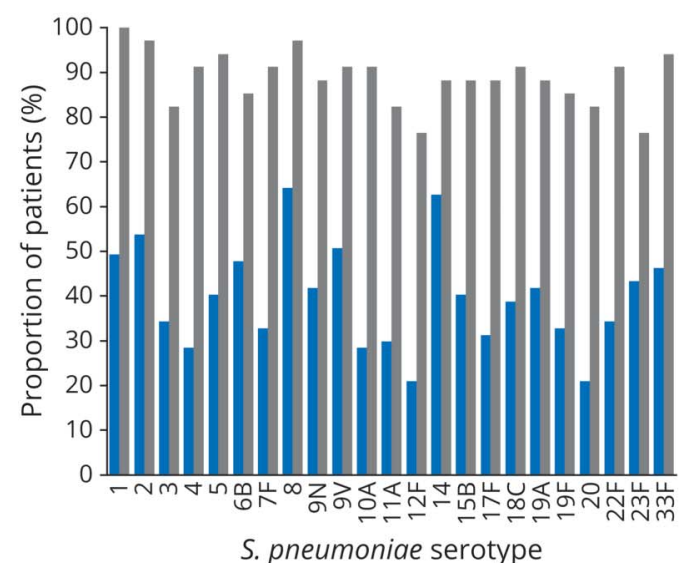

B

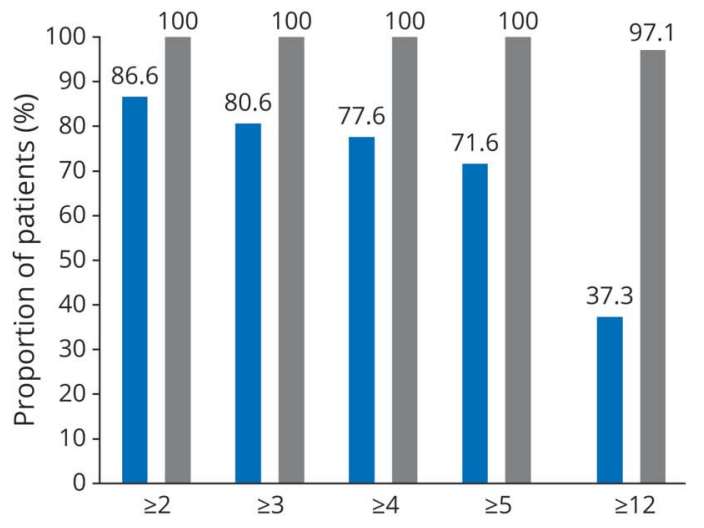

Number of S. pneumoniae serotypes

(A) Positive response to individual Streptococcus pneumoniae serotypes 4 weeks after 23-valent pneumococcal polysaccharide vaccine (23-PPV) administration and (B) positive response to number of $S$ pneumoniae serotypes after 23-PPV administration. Positive response was defined as 2-fold increase or a >1- $\mu$ g/mL $1 \mu \mathrm{g} / \mathrm{mL}$ rise in immunoglobulin G (IgG) level compared with prevaccination levels. DMT = disease-modifying therapy; IFN = interferon; OCR = ocrelizumab. 
Table 2 Influenza vaccine response: prevaccination/postvaccination geometric mean titers

\begin{tabular}{|c|c|c|c|c|}
\hline \multirow[b]{2}{*}{ Strain } & \multicolumn{2}{|l|}{ OCR2, n, GMT (95\% Cl) } & \multicolumn{2}{|l|}{ Control, n, GMT (95\% Cl) } \\
\hline & GMT before vaccination & GMT after vaccination & GMT before vaccination & GMT after vaccination \\
\hline H1N1CA09 & $\mathrm{n}=35,66.3(37.1-118.2)$ & $\mathrm{n}=35,115.3(70.8-187.7)$ & $n=33,39.6(23.0-68.1)$ & $n=33,390.8(264.0-578.4)$ \\
\hline BPHU13 & $n=33,49.3(33.0-73.8)$ & $\mathrm{n}=33,71.3(50.3-100.9)$ & $n=31,27.1(16.4-44.5)$ & $\mathrm{n}=31,189.2(110.8-323.2)$ \\
\hline H3N2SW13 & $\mathrm{n}=30,65.7(38.3-112.9)$ & $\mathrm{n}=30,86.7(52.3-143.9)$ & $n=26,26.1(15.2-45.0)$ & $n=27,324.0(185.9-564.6)$ \\
\hline BBRIS08 & $n=18,33.7(20.6-55.0)$ & $\mathrm{n}=18,49.4(29.1-84.0)$ & $n=16,36.7(16.9-79.7)$ & $\mathrm{n}=16,143.6(55.1-374.4)$ \\
\hline AHK4801 & $\mathrm{n}=5,52.8(21.0-132.6)$ & $\mathrm{n}=5,121.3(70.4-208.8)$ & $n=7,24.4(10.6-56.3)$ & $\mathrm{n}=6,127.0(55.1-292.7)$ \\
\hline
\end{tabular}

Abbreviations: $\mathrm{Cl}$ = confidence interval; GMT = geometric mean titer; OCR = ocrelizumab.

(IgM 1.8-fold, IgG 2.8-fold), 8 weeks (IgM 3.0-fold, IgG 6.1fold), and 12 weeks (IgM 5.1-fold, IgG 11.4-fold) after the first of $3 \mathrm{KLH}$ administrations (figure 5).

\section{Pharmacodynamics}

Mean CD $19^{+}$B-cell counts at baseline in the OCR (all) and control groups were 242 and 205 cells/ $\mu \mathrm{L}$, respectively. In the OCR (all) group, CD19+ B-cell populations in blood were nearly completely depleted by week 2 (mean 0.6 cells $/ \mu \mathrm{L}$; no patients repleted [defined as CD $19+$ B cells $>80$ cells $/ \mu \mathrm{L}])$, and most patients remained depleted through to week 24 (mean 11 cells/ $\mu \mathrm{L}, 2$ patients repleted).

\section{Quantitative immunoglobulin levels}

During the immunization study period, mean IgG levels were stable or slightly higher than baseline levels in both the OCR group (all) and control group. For IgM, a decrease in mean levels was seen from baseline $(1.14 \mathrm{~g} / \mathrm{L})$ to week $24(0.90 \mathrm{~g} / \mathrm{L})$ in the OCR (all) group, while IgM levels remained stable in the control group (table e-3, available from Dryad, doi.org/10. 5061/dryad.crjdfn31d).

\section{Safety during the immunization period}

The safety profiles of the OCR (all) and control groups during the immunization period were not compared directly due to differing durations of this period in the 2 groups. There were

Figure 4 Seroprotection to individual influenza strains

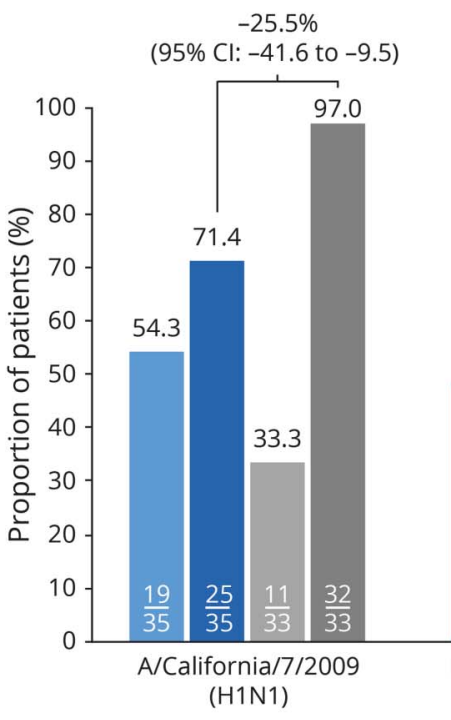

(H1N1)

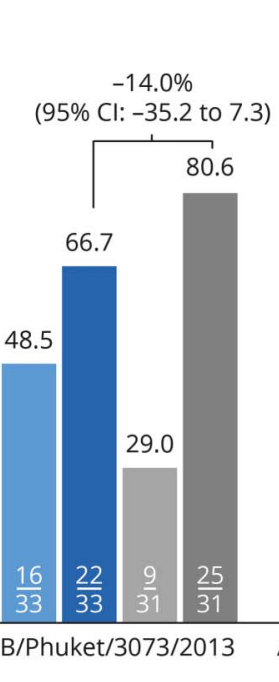

B/Phuket/3073/2013
$-25.9 \%$

(95\% Cl: -45.5 to -6.4$)$
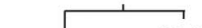

92.6
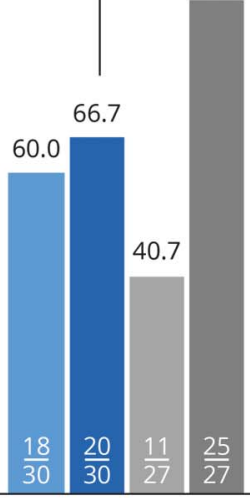

A/Switzerland/9715293/2013

(H3N2)
OCR 2 prevaccination

- OCR 2 postvaccination

Control prevaccination (IFN $\beta$ or no DMT)

- Control postvaccination (IFN $\beta$ or no DMT)

$-3.3 \%$ (95\% Cl: -49.4 to 42.7$)$ 95\% Cl: -50.7 to 11.8$)$
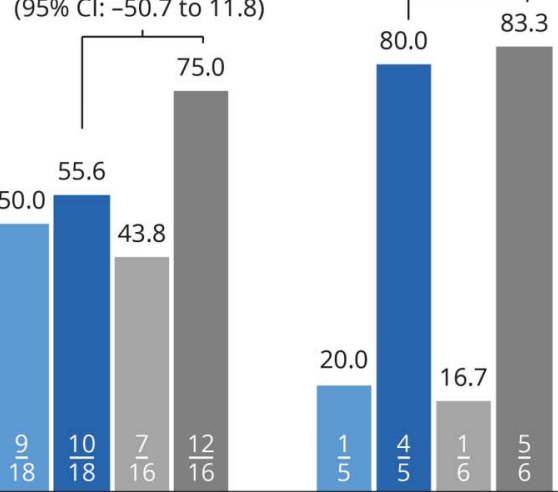

B/Brisbane/60/2008

$\frac{12}{6}$

A/Hong Kong/4801/2014

Influenza strain

Vaccination with World Health Organization Northern Hemisphere-recommended influenza vaccine, seasons 2015/2016 or 2016/2017. Seroprotection defined as a specific hemagglutination inhibition titer $>40 . \mathrm{Cl}=$ confidence interval; DMT = disease-modifying therapy; IFN = interferon; OCR = ocrelizumab. 

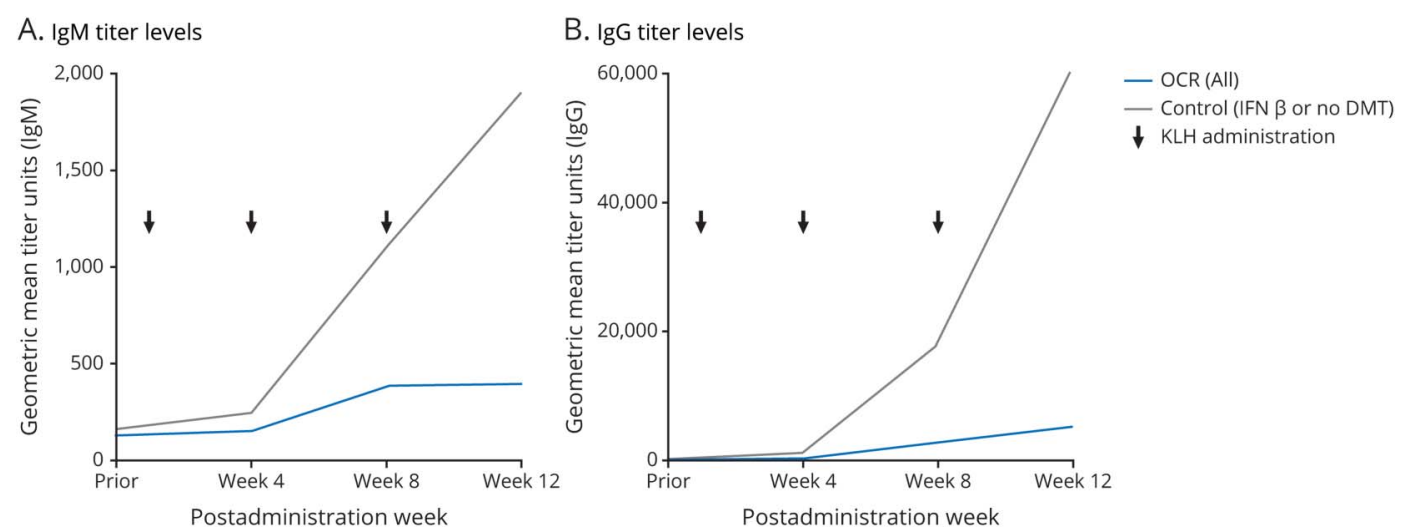

(A) Immunoglobulin (Ig) M and (B) IgG. DMT = disease-modifying therapy; IFN = interferon; KLH = keyhole limpet hemocyanin; OCR = ocrelizumab.

no deaths, serious adverse events, or adverse events leading to study discontinuation in either group during the immunization period. Measures of OCR safety during the immunization period were consistent with the phase III safety profile in patients with $\mathrm{RMS}^{11}$; no new safety signals were identified. A total of 56 of 68 (82.4\%) OCR recipients experienced 275 adverse events, most commonly infusionrelated reactions ( 29 of $68,42.6 \%$ ). Most OCR recipients (50 of $68,73.5 \%$ ) experienced adverse events of mild or moderate intensity (Common Terminology Criteria for Adverse Events [CTCAE] grade 1 or 2); there were no lifethreatening or fatal (CTCAE grade 4/5) events. Thirtytwo of 68 OCR recipients (47.1\%) experienced 56 infection events, mainly ( 30 of $32,93.8 \%$ ) grade 1 or 2 in intensity (including 1 case of influenza in the OCR2 group [CTCAE grade 2] with onset on study day 7, i.e., before influenza vaccine administration); 2 patients had severe (CTCAE grade 3) infections (viral infection, sinusitis). Seventeen of 34 patients (50\%) in the control group experienced 52 adverse events, most commonly nausea $(\mathrm{n}=$ $3[8.8 \%])$ and MS relapse $(n=3[8.8 \%])$. Five control group patients (14.7\%) experienced a total of 6 infection events, 5 of which were mild or moderate in intensity (CTCAE grade 1 or 2 ) and 1 of which (mumps) was severe in intensity (CTCAE grade 3); there were no cases of influenza in the control group.

\section{Discussion}

Vaccinations against infectious diseases are an important part of general health maintenance for patients with MS. Some MS therapies are associated with an increase in infectious disease susceptibility, ${ }^{12,13}$ and MS relapses may emerge as a consequence of infection. ${ }^{14,15}$ The data reported here demonstrate that patients with RMS who are peripherally B-cell depleted after treatment with OCR can mount humoral responses, albeit attenuated, to the inactivated vaccines studied. Live and live-attenuated vaccines were not used due to safety concerns related to the risk of reactivation and are not recommended during OCR treatment and until B-cell repletion. ${ }^{16}$

Humoral responses to both T-cell-dependent antigens such as TT and T-cell-independent antigens such as 23-PPV were attenuated as expected in OCR-treated patients with peripheral B-cell depletion. However, seroprotection or a marked increase in antibody levels could be maintained or achieved after vaccination even in OCR-treated patients.

Among other factors, the humoral response to influenza vaccines depends on the immunogenicity of the strains contained within it. To aid study site compliance, patients in VELOCE received locally available trivalent or quadrivalent seasonal influenza vaccines (2015/2016 or 2016/ 2017) indicated for either 3 or 4 of the 5 strains assessed. Although this eased site compliance, it led to varying strain exposure and complicated the interpretation of some of the influenza results. In addition, by chance, a greater proportion of OCR recipients in the OCR2 group compared with patients in the control group had seroprotective prevaccination titers to most strains tested. This may have been influenced by exposure to influenza vaccines in previous years (strains not recorded). While responses to influenza vaccination in terms of seroprotection and seroconversion (per study protocol and per US Food and Drug Administration guidance for industry) were lower in patients in the OCR2 group than the control group, seroprotection rates in the OCR recipients increased for all tested strains. Interpretation of per-protocol seroconversion, which included a prevaccination $\mathrm{HI}$ titer $<10$ (i.e., seronegativity) to evaluate a patient's neoantigen response to a particular strain, was complicated by the small number of patients who met this criterion. As with the vaccines tested, the response to the neoantigen $\mathrm{KLH}$ in OCR recipients was lower than in control group patients. 
Cellular immune responses to the vaccines and $\mathrm{KLH}$ were not studied.

These results also support previous phase III study observations demonstrating that OCR-treated patients maintained their preexisting specific humoral immunity to common viral (figure e-3, available from Dryad, doi.org/10. 5061/dryad.crjdfn31d) and bacterial antigens (mean change [SD] in Streptococcus pneumoniae at week 96 vs baseline was $-1.13[40.25] \mathrm{mg} / \mathrm{L}$ and $-1.99[59.60] \mathrm{mg} / \mathrm{L}$ in the IFN- $\beta$-1a and OCR groups, respectively) achieved before OCR initiation. ${ }^{17}$ Evidence suggests that the attenuated responses in VELOCE may be a class effect shared with other CD20+ B-cell-depleting therapies. For example, findings from studies of rituximab in patients with lymphoma and lupus receiving rituximab demonstrate an attenuated response to TT. ${ }^{18-20}$ In another trial of rituximab in patients with rheumatoid arthritis, ${ }^{21}$ responses to 23 PPV and KLH were observed in patients treated with rituximab plus methotrexate but were lower than in patients treated with methotrexate alone. Studies have also indicated that rituximab attenuates the response to influenza vaccine, ${ }^{22-24}$ which appeared to be inversely related to the degree of B-cell recovery at the time of vaccination. ${ }^{24}$ In a further analysis of humoral immunity after repeat rituximab treatment over 1 year in patients with rheumatoid arthritis, the proportions of patients with positive antibody titers against $S$ pneumoniae, influenza, mumps, rubella, varicella, and TT were generally similar to the proportions at baseline. ${ }^{25}$

The effect of OCR treatment on vaccine response in patients with PPMS was not evaluated in this study. While the MS disease course itself (i.e., progressive vs relapsing) would not be expected to affect vaccine responses, increased age is known to be associated with decreased vaccine responses, and because patients with PPMS tend to be older, they may experience a reduced vaccine response on OCR. Furthermore, the durability of responses to vaccines instituted during anti-CD20 treatment is unknown and should be the subject of future study.

Patients with RMS in this study who were peripherally B-cell depleted after treatment with OCR could mount humoral responses, albeit decreased, to clinically relevant vaccines (TT, 23-PPV, influenza) and the neoantigen KLH. Whenever possible, vaccination requirements should be completed as per local prescribing information before the initiation of OCR, ${ }^{16}$ which will optimize vaccine effectiveness. Nonetheless, vaccination even after OCR initiation is likely to generate a meaningful vaccine response in most patients and may be considered when vaccination is deemed useful. For example, it is recommended to vaccinate patients on OCR with seasonal influenza vaccine to generate what will potentially be a protective humoral response to the vaccine, even if attenuated. OCR-treated patients should not receive any live vaccine, either during OCR treatment or after OCR, until B cells have been repleted. ${ }^{16}$

\section{Acknowledgment}

The authors thank all patients, their families, and the investigators who participated in this trial.

\section{Study funding}

This research was funded by F. Hoffmann-La Roche Ltd, Basel, Switzerland. Writing and editorial assistance was provided by Articulate Science, UK, and funded by F. HoffmannLa Roche Ltd.

\section{Disclosure}

A. Bar-Or has served on scientific advisory boards for Biogen, F. Hoffmann-La Roche Ltd and Genentech, Inc, GlaxoSmithKline plc, Guthy-Jackson/GGF, MedImmune, Merck/EMD Serono, Receptos/Celgene, and Sanofi Genzyme; has received grants from the Canadian Institute for Health Research, the Multiple Sclerosis Society Canada, the National MS Society and the NIH; and has received research support from Biogen, Genentech, Inc., Novartis, and Sanofi Genzyme. J.C. Calkwood has received research revenue from Biogen, Celgene, Genentech, Inc, Genzyme MedDay, and Novartis, as well as compensation for advisory boards and promotional programs from Biogen, Celgene, EMD Serono, Genentech, Inc, Genzyme, and Novartis. C. Chognot and J. Evershed are employees of F. Hoffmann-La Roche Ltd. E.J. Fox has received speaker honoraria and travel expense reimbursement from, participated in clinical research or speakers bureaus for, or served on advisory/consulting/steering committees for AbbVie, Acorda, Allergan, Bayer, Biogen, Celgene, Chugai, EMD Serono, F. Hoffmann-La Roche Ltd, Mallinckrodt, MedDay, Novartis, Sanofi Genzyme, Teva, and TG Therapeutics. A. Herman is an employee of Genentech, Inc and a shareholder of F. Hoffmann-La Roche Ltd. M. Manfrini is an employee and shareholder of F. Hoffmann-La Roche Ltd. J. McNamara is an employee of John McNamara Consulting Ltd. D.S. Robertson reports grants from F. Hoffman-La Roche Ltd/ Genentech, Inc, Actelion, MedImmune, MedDay Pharmaceuticals, Patient-Centered Outcomes Research Institute, SunPharma, and TG Therapeutics; consulting fees from Celgene; grants and consulting fees from Mallinckrodt; grants and personal fees from Biogen, Genzyme, EMD Serono, F. Hoffman-La Roche Ltd/Genentech, Inc, and Novartis; and personal fees from Teva, Acorda, Mallinckrodt, and Consortium of Multiple Sclerosis Centers. D. Stokmaier is an employee of F. HoffmannLa Roche Ltd. J.K. Wendt has received speaker fees from Genentech, Inc, EMD Serono, and Genzyme. K.L. Winthrop is a consultant for GlaxoSmithKline plc, F. Hoffmann-La Roche Ltd, and Pfizer Inc. A. Traboulsee reports grants from F. Hoffman-La Roche Ltd, Chugai, the Canadian Institute for Health Research, and Multiple Sclerosis Society Canada; grants and personal fees from Biogen Idec and Sanofi Genzyme; and personal fees from Novartis, Teva Innovation, Consortium of Multiple Sclerosis Centers, and F. Hoffman-La Roche Ltd. Go to Neurology.org/N for full disclosures.

\section{Publication history}

Received by Neurology May 15, 2019. Accepted in final form April 20, 2020. 
Appendix Authors

\begin{tabular}{lll}
\hline Name & Location & Contribution \\
\hline Amit Bar- & Perelman School of & Designed/conceptualized \\
Or, MD, & Medicine, University of & $\begin{array}{l}\text { study; interpreted the data; } \\
\text { frafted the manuscript for }\end{array}$ \\
FRCPC & $\begin{array}{l}\text { Pennsylvania, } \\
\text { Philadelphia }\end{array}$ & $\begin{array}{l}\text { intellectual content } \\
\end{array}$
\end{tabular}

\begin{tabular}{|c|c|c|}
\hline $\begin{array}{l}\text { Jonathan C. } \\
\text { Calkwood, } \\
\text { MD }\end{array}$ & $\begin{array}{l}\text { The Minneapolis Clinic of } \\
\text { Neurology, MN }\end{array}$ & $\begin{array}{l}\text { Site principal investigator; } \\
\text { revised the manuscript for } \\
\text { intellectual content }\end{array}$ \\
\hline $\begin{array}{l}\text { Cathy } \\
\text { Chognot, } \\
\text { PhD }\end{array}$ & $\begin{array}{l}\text { F. Hoffmann-La Roche Ltd, } \\
\text { Basel, Switzerland }\end{array}$ & $\begin{array}{l}\text { Conduct of study; } \\
\text { interpreted the data; } \\
\text { revised the manuscript for } \\
\text { intellectual content }\end{array}$ \\
\hline $\begin{array}{l}\text { Joanna } \\
\text { Evershed, } \\
\text { BSc }\end{array}$ & $\begin{array}{l}\text { F. Hoffmann-La Roche Ltd, } \\
\text { Basel, Switzerland }\end{array}$ & $\begin{array}{l}\text { Conduct of study; revised } \\
\text { the manuscript for } \\
\text { intellectual content }\end{array}$ \\
\hline $\begin{array}{l}\text { Edward J. } \\
\text { Fox, MD, } \\
\text { PhD }\end{array}$ & $\begin{array}{l}\text { Central Texas Neurology } \\
\text { Consultants, Round Rock }\end{array}$ & $\begin{array}{l}\text { Site principal investigator; } \\
\text { revised the manuscript for } \\
\text { intellectual content }\end{array}$ \\
\hline $\begin{array}{l}\text { Ann E. } \\
\text { Herman, } \\
\text { PhD }\end{array}$ & $\begin{array}{l}\text { Genentech, Inc, South San } \\
\text { Francisco, CA }\end{array}$ & $\begin{array}{l}\text { Designed/conceptualized } \\
\text { study; interpreted the data; } \\
\text { revised the manuscript for } \\
\text { intellectual content }\end{array}$ \\
\hline
\end{tabular}

\begin{tabular}{|c|c|c|}
\hline $\begin{array}{l}\text { Marianna } \\
\text { Manfrini, } \\
\text { MD, PhD }\end{array}$ & $\begin{array}{l}\text { F. Hoffmann-La Roche Ltd, } \\
\text { Basel, Switzerland }\end{array}$ & $\begin{array}{l}\text { Interpreted the data; } \\
\text { revised the manuscript for } \\
\text { intellectual content }\end{array}$ \\
\hline $\begin{array}{l}\text { John } \\
\text { McNamara, } \\
\text { MSc }\end{array}$ & $\begin{array}{l}\text { John McNamara } \\
\text { Consulting Ltd, } \\
\text { Cambridge, UK }\end{array}$ & $\begin{array}{l}\text { Statistical analysis; revised } \\
\text { the manuscript for } \\
\text { intellectual content }\end{array}$ \\
\hline $\begin{array}{l}\text { Derrick S. } \\
\text { Robertson, } \\
\text { MD }\end{array}$ & $\begin{array}{l}\text { University of South } \\
\text { Florida, Tampa }\end{array}$ & $\begin{array}{l}\text { Site principal investigator; } \\
\text { revised the manuscript for } \\
\text { intellectual content }\end{array}$ \\
\hline $\begin{array}{l}\text { Daniela } \\
\text { Stokmaier, } \\
\text { PhD }\end{array}$ & $\begin{array}{l}\text { F. Hoffmann-La Roche Ltd, } \\
\text { Basel, Switzerland }\end{array}$ & $\begin{array}{l}\text { Designed/conceptualized } \\
\text { study; conduct of study; } \\
\text { interpreted the data; } \\
\text { drafted the manuscript for } \\
\text { intellectual content }\end{array}$ \\
\hline $\begin{array}{l}\text { Jeanette K. } \\
\text { Wendt, MD }\end{array}$ & $\begin{array}{l}\text { Territory Neurology and } \\
\text { Research Institution, } \\
\text { Tucson, AZ }\end{array}$ & $\begin{array}{l}\text { Site principal investigator; } \\
\text { revised the manuscript for } \\
\text { intellectual content }\end{array}$ \\
\hline $\begin{array}{l}\text { Kevin L. } \\
\text { Winthrop, } \\
\text { MD, MPH }\end{array}$ & $\begin{array}{l}\text { Oregon Health \& Science } \\
\text { University, Portland }\end{array}$ & $\begin{array}{l}\text { Interpreted the data; } \\
\text { revised the manuscript for } \\
\text { intellectual content }\end{array}$ \\
\hline $\begin{array}{l}\text { Anthony } \\
\text { Traboulsee, } \\
\text { MD, FRCPC }\end{array}$ & $\begin{array}{l}\text { University of British } \\
\text { Columbia, Vancouver, } \\
\text { Canada }\end{array}$ & $\begin{array}{l}\text { Site principal investigator; } \\
\text { interpreted the data; } \\
\text { revised the manuscript for } \\
\text { intellectual content }\end{array}$ \\
\hline
\end{tabular}

\section{References}

1. Genovese MC, Kaine JL, Lowenstein MB, et al. Ocrelizumab, a humanized antiCD20 monoclonal antibody, in the treatment of patients with rheumatoid arthritis: a phase I/II randomized, blinded, placebo-controlled, dose-ranging study. Arthritis Rheum 2008;58:2652-2661.
2. Klein C, Lammens A, Schafer W, et al. Response to: monoclonal antibodies targeting CD20. MAbs 2013;5:337-338.

3. Martin F, Chan AC. B cell immunobiology in disease: evolving concepts from the clinic. Annu Rev Immunol 2006;24:467-496.

4. DiLillo DJ, Hamaguchi Y, Ueda Y, et al. Maintenance of long-lived plasma cells and serological memory despite mature and memory B cell depletion during CD20 immunotherapy in mice. J Immunol 2008;180:361-371.

5. Polman CH, Reingold SC, Edan G, et al. Diagnostic criteria for multiple sclerosis: 2005 revisions to the "McDonald criteria." Ann Neurol 2005;58: $840-846$.

6. Schwid SR, Decker MD, Lopez-Bresnahan M; Rebif-Influenza Vaccine Study Investigators. Immune response to influenza vaccine is maintained in patients with multiple sclerosis receiving interferon beta-1a. Neurology 2005;65: 1964-1966.

7. Olberg HK, Cox RJ, Nostbakken JK, Aarseth JH, Vedeler CA, Myhr KM. Immunotherapies influence the influenza vaccination response in multiple sclerosis patients: an explorative study. Mult Scler 2014;20:1074-1080.

8. Mehling M, Fritz S, Hafner P, et al. Preserved antigen-specific immune response in patients with multiple sclerosis responding to IFNbeta-therapy. PLoS One 2013;8 e78532.

9. Olberg HK, Eide GE, Cox RJ, et al. Antibody response to seasonal influenza vaccination in patients with multiple sclerosis receiving immunomodulatory therapy. Eur $\mathrm{J}$ Neurol 2018;25:527-534

10. US Food and Drug Administration. Guidance for industry: clinical data needed to support the licensure of pandemic influenza vaccines. 2007. Available at: fda.gov/ downloads/BiologicsBloodVaccines/GuidanceComplianceRegulatoryInformation/ Guidances/Vaccines/UCM091985.pdf. Accessed November 2018.

11. Hauser SL, Bar-Or A, Comi G, et al. Ocrelizumab versus interferon beta-1a in relapsing multiple sclerosis. N Engl J Med 2017;376:221-234.

12. Pellegrino $\mathrm{P}$, Carnovale $\mathrm{C}$, Perrone V, et al. Efficacy of vaccination against influenza in patients with multiple sclerosis: the role of concomitant therapies. Vaccine 2014;32: $4730-4735$.

13. Loebermann M, Winkelmann A, Hartung HP, Hengel H, Reisinger EC, Zettl UK. Vaccination against infection in patients with multiple sclerosis. Nat Rev Neurol 2012; $8: 143-151$.

14. Correale J, Fiol M, Gilmore W. The risk of relapses in multiple sclerosis during systemic infections. Neurology 2006;67:652-659.

15. Confavreux C, Suissa S, Saddier P, Bourdes V, Vukusic S; Vaccines in Multiple Sclerosis Study Group. Vaccinations and the risk of relapse in multiple sclerosis: Vaccines in Multiple Sclerosis Study Group. N Engl J Med 2001;344: 319-326.

16. Genentech. Ocrevus: highlights of prescribing information. 2019. Available at: gene. com/download/pdf/ocrevus prescribing.pdf. Accessed December 2019.

17. Bar-Or A, Arnold DL, Comi G, et al. Effect of ocrelizumab on humoral immunity markers in the phase iii, double-blind, double-dummy, interferon $\beta$-1a-controlled OPERA I and OPERA II studies. Poster DX12 presented at 2016 Annual Meeting of the Consortium of Multiple Sclerosis Centers (CMSC); June 1-4, 2016; National Harbor, MD. Presentation available at: cmsc.confex.com/.../2016/webprogram/ Handout/Paper4280/DX12.pdf. Accessed December 2019.

18. van der Kolk LE, Baars JW, Prins MH, van Oers MH. Rituximab treatment results in impaired secondary humoral immune responsiveness. Blood 2002;100 $2257-2259$

19. van der Kolk LE, Grillo-Lopez AJ, Baars JW, van Oers MH. Treatment of relapsed B-cell non-Hodgkin's lymphoma with a combination of chimeric anti-CD20 monoclonal antibodies (rituximab) and G-CSF: final report on safety and efficacy. Leukemia 2003;17:1658-1664.

20. Albert D, Dunham J, Khan S, et al. Variability in the biological response to anti-CD20 B cell depletion in systemic lupus erythaematosus. Ann Rheum Dis 2008;67: 1724-1731.

21. Bingham CO III, Looney RJ, Deodhar A, et al. Immunization responses in rheumatoid arthritis patients treated with rituximab: results from a controlled clinical trial. Arthritis Rheum 2010;62:64-74.

22. Westra J, van Assen S, Wilting KR, et al. Rituximab impairs immunoglobulin (ig)M and IgG (subclass) responses after influenza vaccination in rheumatoid arthritis patients. Clin Exp Immunol 2014;178:40-47.

23. van Assen S, Holvast A, Benne CA, et al. Humoral responses after influenza vaccination are severely reduced in patients with rheumatoid arthritis treated with rituximab. Arthritis Rheum 2010;62:75-81.

24. Eisenberg RA, Jawad AF, Boyer J, et al. Rituximab-treated patients have a poor response to influenza vaccination. J Clin Immunol 2013;33:388-396.

25. European Mabthera (rituximab) summary of product characteristics. 2018. Available at: medicines.org.uk/emc/product/3801/smpc. Accessed June 26, 2018. 


\section{Neurology}

\section{Effect of ocrelizumab on vaccine responses in patients with multiple sclerosis: The VELOCE study \\ Amit Bar-Or, Jonathan C. Calkwood, Cathy Chognot, et al.}

Neurology 2020;95;e1999-e2008 Published Online before print July 29, 2020

DOI 10.1212/WNL.0000000000010380

This information is current as of July 29, 2020

\section{Updated Information \& Services}

References

Citations

Subspecialty Collections

Permissions \& Licensing

Reprints including high resolution figures, can be found at: http://n.neurology.org/content/95/14/e1999.full

This article cites 21 articles, 5 of which you can access for free at: http://n.neurology.org/content/95/14/e1999.full\#ref-list-1

This article has been cited by 11 HighWire-hosted articles: http://n.neurology.org/content/95/14/e1999.full\#\#otherarticles

This article, along with others on similar topics, appears in the following collection(s):

\section{All Immunology}

http://n.neurology.org/cgi/collection/all_immunology

All Infections

http://n.neurology.org/cgi/collection/all_infections

\section{Class II}

http://n.neurology.org/cgi/collection/class_ii

Clinical trials Randomized controlled ( $\overline{\mathbf{C} O N S O R T}$ agreement)

http://n.neurology.org/cgi/collection/clinical_trials_randomized_contro

lled_consort_agreement

Multiple sclerosis

http://n.neurology.org/cgi/collection/multiple_sclerosis

Information about reproducing this article in parts (figures,tables) or in its entirety can be found online at:

http://www.neurology.org/about/about_the_journal\#permissions

Information about ordering reprints can be found online:

http://n.neurology.org/subscribers/advertise

Neurology ${ }^{\circledR}$ is the official journal of the American Academy of Neurology. Published continuously since 1951, it is now a weekly with 48 issues per year. Copyright @ 2020 American Academy of Neurology. All rights reserved. Print ISSN: 0028-3878. Online ISSN: 1526-632X.

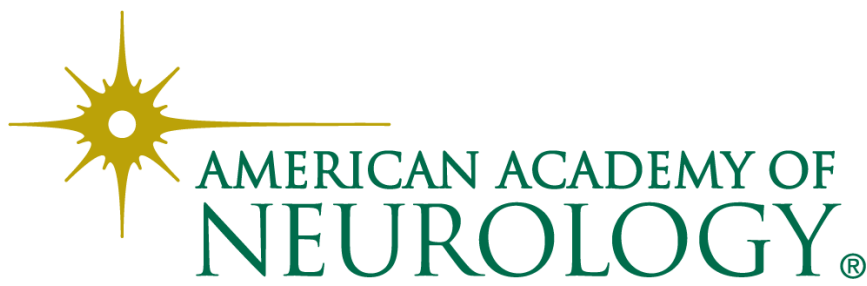

